\title{
Multireference Configuration Interaction Methods - An Application to the Valence Isomerism in Cyclobutadieno-p-benzoquinone and its Diprotonated Form
}

\author{
Mario Vazdar, Mirjana Eckert-Maksić*
}

\author{
Laboratory for Physical Organic Chemistry, Division of Organic Chemistry and Biochemistry, Ruđer Bošković Institute, POB 180, Zagreb, Croatia \\ * Corresponding author's e-mail address: mmaksic@emma.irb.hr \\ RECEIVED: October 28, $2015 *$ REVISED: December 23, $2015 *$ ACCEPTED: December 24, 2015
}

THIS PAPER IS DEDICATED TO DR. SVETOZAR MUSIĆ ON THE OCCASION OF HIS 70"7h BIRTHDAY

\begin{abstract}
Multireference averaged quadratic coupled cluster (MR-AQCC) calculations for cyclobutadieno-p-benzoquinone indicate that valence bond isomers $1 \mathrm{a}$ and $1 \mathrm{~b}$ can exist as distinct species. The energy barrier height for their interconversion are 4.6 and $4.5 \mathrm{kcal} \mathrm{mol}^{-1}$, respectively, what is by ca. $2 \mathrm{kcal} \mathrm{mol}^{-1}$ lower than in the parent cyclobutadiene, implying that they could perhaps exist only under extreme conditions, namely at very low temperatures. For double protonated cyclobutadieno-p-benzoquinone, the CASSCF calculations erroneously predict existence of two valence isomers, $2 a$ and $2 b$, whereas the MR-AQCC calculations reveal that geometry of the double protonated species could be best described by structure $\mathbf{2 b}$. This nicely illustrates the crucial role of dynamic correlation and the need for using a highly-correlated theoretical method including geometry optimization in studied molecules.
\end{abstract}

Keywords: cyclobutadieno-p-benzoquinone, multrireference calculations, valence isomerism, energy barriers.

\section{INTRODUCTION}

B OND stretch isomerization, which is defined as isomerization of two isoenergetic thermodinamically stable minimum structures on a potential energy surface that differ only in their bond lengths appears to be among most controversial concepts in chemistry. ${ }^{[1-4]} \mathrm{A}$ paradigmatic example of the bond stretch isomerism which includes the localized $\pi$-double bond shift mechanism as an underlying electronic effect is provided by cyclobutadiene (CBD), the smallest neutral antiaromatic organic compound, with a high angular strain which is reflected in its highly pronounced reactivity. ${ }^{[5]}$ Due to this reasons, synthesis of CBD has been a great challenge during last decades. ${ }^{[6-9]}$ In a seminal experiment, Cram and coworkers have succeeded to isolate CBD in a hemicarcerand matrix but the crystal structure of cyclobutadiene could not been determined. ${ }^{[10]}$ More recently, Barboiu and coworkers have claimed to identify two kinetically stable isomeric forms (rectangular and square) of 1,3-dimethylcyclobutadiene in the matrix at 175 $\mathrm{K}$ by $\mathrm{X}$-ray spectroscopy, ${ }^{[11]}$ which according to numerous calculations correspond to ground state and transition structure, respectively. ${ }^{[12,13]}$ However, this finding initiated heated debate in literature on whether the measured crystal structure corresponds to 1,3-dimethylcyclobutadiene at al. ${ }^{[14-17]}$

Valence bond isomerism of cyclobutadiene has also aroused considerable interest of theoretical chemists, to mention only the most recent high level computational studies by Balkova and Bartlett, ${ }^{[12]}$ Sancho-Garcia et al., ${ }^{[18]}$ Shen et al., ${ }^{[19]}$ Lefrancois et al., ${ }^{[20]}$ and our research group. ${ }^{[13]}$ We have shown that the barrier for automerization reaction of the parent $C B D$ molecule obtained at the MR-AQCC level of theory including extrapolations to the basis set limit is $6.3 \mathrm{kcal} \mathrm{mol}^{-1}$. $^{[13]}$ This value is $2.2 \mathrm{kcal} \mathrm{mol}^{-1}$ above the two determinant $\operatorname{TDCCSD}(T)$ result of Balková and Bartlett. ${ }^{[12]}$ The state specific multireference BrillouinWigner CC (MR BWCC) theory gives $4.5 \mathrm{kcal} \mathrm{mol}^{-1,},{ }^{[18]}$ 
<smiles>C=C=C1[C]=[Si]2[C]1C(=O)C=CC2=O</smiles>

1a<smiles></smiles>

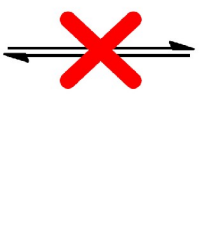

2a<smiles>C=[Si]1C(=O)C=C[Si]C1=O</smiles>

1b

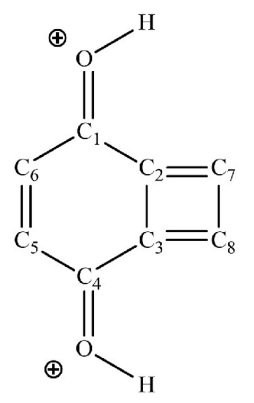

2b

Figure 1. Valence bond isomerism in the neutral and diprotonated cyclobutadieno-p-benzoquinones.

whereas the recent block correlated coupled cluster CASBCCC4 method yields $6.2 \mathrm{kcal} \mathrm{mol}^{-1} .{ }^{[19]}$ Except for cyclobutadiene MR-AQCC calculations were also performed on derivatives of $\mathrm{CBD}$, such as benzo[1,2:4,5]dicyclobutadiene, ${ }^{[21,22]}$ and cyano substituted CBDs. ${ }^{[23]}$ For all these molecules isomerization barrier compared to parent CBD was found to be somewhat lower, being around $5 \mathrm{kcal}$ $\mathrm{mol}^{-1}$. These indicates that the existence of valence bond isomers in these molecules could be possible only at very low temperatures due to the low energy barrier interconnecting two minima on the potential energy surface.

Another interesting set of molecules for studying the effect of annelation on the $\pi$-bond shifting which aroused considerable attention is given by benzoquinones annelated with the cyclobutene ring, with cyclobutadieno- $p$-benzoquinone being studied in most details. ${ }^{[24-27]}$ Similarly to cyclobutadiene, cyclobutadieno- $p$-benzoquinone has not been synthesized as yet, but a synthesis of naphthoquinone-fused cyclobutadiene ruthenium complexes ${ }^{[28]}$ and dibenzoquinone cyclobutadiene derivative ${ }^{[29]}$ has been reported. The first computational study of the $\pi$-bond shifting in cyclobutadieno-p-benzoquinone using HF/6-31G(d) and B3LYP/6-31G(d) method was reported by McKee et al.[24] They found that valence isomers $\mathbf{1 a}$ and $\mathbf{1 b}$ (Figure $\mathbf{1}$ ) are true minima at the potential energy surface, but due to single-determinant approach used in calculations, they

were not able to locate the transition structure for their interconversion.

The same holds for recent MP2 and B3LYP calculations of Golas et al. ${ }^{[30]}$ The only study carried at higher CASPT2//GVB2 level of theory which adequately included electron correlation, has revealed that structure $\mathbf{1} \mathbf{b}$ is not kinetically stable at the potential energy surface with isomerization barrier of only $0.3 \mathrm{kcal} \mathrm{mol}^{-1}$. [25] It should be mention, however, that these results have been obtained by single point CASPT2 calculations which did not provide efficient geometry optimization of minima and transition structures. In order to remedy for this drawback we deemed it worthwile to reexamine possibility of existence of two valence bond isomers $\mathbf{1 a}$ and $\mathbf{1 b}$ by using more advanced multireference average quadratic coupled cluster method (MR-AQCC) ${ }^{[31-33]}$ which was proved to provide reliable description of valence bond isomerism in our previous study of cyclobutadiene.[13] This will give us opportunity to compare the results with those of cylobutadiene obtained at the same level of theory and thus allow reliable estimate of annelation effect on the electronic structure and $\pi$-bond shifting in the parent molecule. We should mention at this point that practically identical results for automerization of cyclobutadiene were obtained using MR-CISD+Q method, ${ }^{[13]}$ but for the sake of comparison with previously reported MR$A Q C C$ results for variety of cyclobutadiene derivatives studied in our group, ${ }^{[21,23]}$ only MR-AQCC calculations will be performed here. In addition to the study of $\pi$-bond shifting in the neutral cyclobutadieno- $p$-benzoquinone, we shall briefly address effect of diprotonation of the quinone ring on the overall geometry of molecule. A key question of interest here is whether Kekule structures related to isomers $\mathbf{1 a}$ and $\mathbf{1} \mathbf{b}$ in the neutral molecule have their counterparts ( $\mathbf{2 a}$ and $\mathbf{2 b}$ ) in the double protonated molecule (Figure 1). Special attention will be paid to impact of redistribution of electron density induced by protonation of the carbonyl groups on location of the double bonds in the cyclobutadiene moiety.

\section{METHODOLOGY}

Multiconfigurational and multireference computational methods are widely used in cases where nondynamical electron correlation effects, together with the ever-present dynamic electron correlation, represent an important contribution in total electronic wavefunction. ${ }^{[34]}$ In case of standard single reference methods, such as Hartree-Fock, post-Hartree-Fock, and density functional based methods, a total electronic wavefunction is determined by a single Slater determinant and nondynamical electron correlation does not play an important role. In most of the routine quantum chemical calculations, this approximation is more than sufficient for an adequate description of electronic properties if dynamic electronic correlation effects are 
properly taken into account. Today, this is readily achieved by use of standard density functional theory (DFT) or postHartree-Fock methods, such as Møller-Plesset perturbation theory (MP2) or coupled cluster (CC) methods provided that sufficiently flexible basis sets of at least double-zeta quality are used. However, in special cases, such as bond creating/breaking, ${ }^{[35]}$ excited states calculation ${ }^{[36]}$ or quasidegenerative ground states, ${ }^{[37]}$ the single reference approximation breaks down resulting in a qualitatively wrong description of a given electronic system. This occurs due to the inability of single reference methods to properly account for the nondynamic electron correlation arising from degenerate molecular orbitals which are always present in given situations. In this respect, a number of multi-configurational methods, based on a linear combination of selected degenerate molecular orbitals participating in a chemical reaction, were developed. One of the commonly used methods is the multi-configurational self-consistent field (MCSCF) method. ${ }^{[38]}$ It uses a linear combination of several electronic configurations, each with its own coefficient, and by using a variational principle the total wavefunction with the lowest energy is obtained by simultaneous optimization of electronic configurations and their coefficients. In order to account for dynamical electron correlation effects, MCSCF wave function is often used as a reference state for the multireference configuration interaction $(\mathrm{MRCl})^{[39]}$ or complete active space perturbation theory (CASPT2) ${ }^{[40]}$ calculations. In case of CASPT2 methods dynamical correlation is described by the perturbation theory of the multiconfigurational MCSCF wavefunction, similar to the MP2 method in single reference methods. On the other hand, in $\mathrm{MRCl}$ methods, the total wavefunction is obtained by all single and double electron excitations from the reference state to the virtual space limited by the size of a given basis set. Particularly valuable among them are analytic energy gradient methods, like the multireference averaged quadratic coupled cluster ${ }^{[31]}$ (MR-AQCC) method which enables straightforward computation of analytic energy gradients, thus allowing an efficient optimization of the energy minima and transition-state structures on the PES and straightforward calculation of the ZPVEs. Consequently, it allows detailed inspection of chemical reactions along the reaction paths by treating both dynamic and nondynamic electron correlation on the same footing offering a unified description of widely different electronic structures occurring in the ground, transition and excited states of the same molecule. This feature is of the outmost importance in the study of the bond-stretch isomerization where the transition structure for isomerization cannot be properly described by the single reference methods. ${ }^{[13,21,23]}$ Apart from that, $\mathrm{MRCl}$ methods are frequently used for calculating static electronic properties, such as vertical and adiabatic excitation energies or transition dipole moments, ${ }^{[41-44]}$ and dynamical aspects of a fate of photoexcited molecules. ${ }^{[45-51]}$

Finally, it should be stressed that use of MCSCF, and especially $\mathrm{MRCl}$ methods, is often computationally too expensive which limits their application to relatively small molecules containing no more than 10-15 heavy atoms.

\section{COMPUTATIONAL DETAILS}

Complete active space self-consisted field (CASSCF) ${ }^{[40]}$ and multi reference average-quadratic coupled cluster (MR$A Q C C)^{[31-33]}$ calculations were performed for the molecules presented in Figure 1. $C_{2 v}$ symmetry restriction was always employed unless stated otherwise. All molecules are planar and lie in the $y z$ plane. In the CASSCF calculations, the complete active space (CAS) wave function was comprised of 10 $\pi$ electrons distributed over $10 \pi$ orbitals $\left(1 b_{1}, 2 b_{1}, 3 b_{1}, 4 b_{1}\right.$, $5 b_{1}, 1 a_{2}, 2 a_{2}, 3 a_{2}, 4 a_{2}$ and $\left.5 a_{2}\right)$. The dynamic correlation energy was taken into the account by using MR-AQCC method. It should be pointed out that this modified MRCISD approach includes size-extensivity corrections in an iterative way. Also, it incorporates analytical gradients ${ }^{[39,41,52]}$ which provide the geometry optimization feasible at very high level of theory. The final expansion space in terms of configuration state functions (CSFs) for MR-AQCC calculations, was obtained by allowing all single and double excitations from all reference configurations into all internal and virtual orbitals. In the geometry optimizations, the symmetry of the reference configurations was restricted to the state symmetry, and the interacting space restriction was applied. ${ }^{[53]}$ The ten core electrons of carbon and oxygen atoms have been kept frozen in all calculations.

It should be stressed that the use of full CAS $(10,10)$ active space as a reference space would be too demanding for the present computational capabilities. Therefore, the construction of the final reference space was modified based on the natural orbital (NO) occupation ( $n_{\text {occ }}$ ) obtained at the CASSCF level of theory. ${ }^{[43]}$ Namely, the $1 b_{1}$ orbital has the largest orbital occupation ( $n_{\text {occ }}=1.944,1.943$ and 1.943 in structures $\mathbf{1 a}, \mathbf{1 b}$ and transition structure $\mathbf{1 T S}$, respectively). Therefore, this orbital was kept doubly occupied in all reference configurations. On the other hand, the orbital occupation of $5 \mathrm{a}_{2}$ orbital has a very small value $\left(n_{\text {occ }}=0.045\right.$, 0.046 and 0.047 in structures $\mathbf{1 a}, \mathbf{1} \mathbf{b}$ and transition structure 1TS, respectively) and was moved to the external space. The remaining eight orbitals $\left(2 b_{1}, 3 b_{1}, 4 b_{1}, 5 b_{1}, 1 a_{2}\right.$, $2 a_{2}, 3 a_{2}$ and $4 a_{2}$ ) were also classified based on their NO occupation numbers (Table 1 ).

Thus, data in Table 1 show that two orbitals $\left(2 b_{1}\right.$ and $1 a_{2}$ ) in the neutral molecule have occupation number close to the value of 1.9 in all structures. Also, two orbitals $\left(5 b_{1}\right.$ and $4 \mathrm{a}_{2}$ ) are very weakly occupied, with the occupation number close to 0 . This enables grouping of orbitals $1 a_{2}$ and 
Table 1 . The natural orbital occupation number $n_{\text {occ }}$ for molecules $1 \mathrm{a}, 1 \mathrm{~b}$ and transition structure 1TS obtained by the $\operatorname{CASSCF}(10,10) / 6-31 G(d)$ level of theory

\begin{tabular}{cccccccccccc}
\hline & $1 \mathrm{~b}_{1}$ & $2 \mathrm{~b}_{1}$ & $3 \mathrm{~b}_{1}$ & $4 \mathrm{~b}_{1}$ & $5 \mathrm{~b}_{1}$ & $1 \mathrm{a}_{2}$ & $2 \mathrm{a}_{2}$ & $3 \mathrm{a}_{2}$ & $4 \mathrm{a}_{2}$ & $5 \mathrm{a}_{2}$ \\
\hline $1 \mathrm{a}$ & 1.944 & 1.911 & 1.879 & 1.772 & 0.066 & 1.926 & 0.240 & 0.130 & 0.085 & 0.045 \\
$1 \mathrm{~b}$ & 1.943 & 1.906 & 1.881 & 0.267 & 0.065 & 1.929 & 1.734 & 0.142 & 0.085 & 0.046 \\
$1 \mathrm{TS}$ & 1.943 & 1.903 & 1.873 & 0.810 & 0.067 & 1.927 & 1.125 & 0.146 & 0.089 & 0.047 \\
\hline
\end{tabular}

$2 b_{1}$ into restricted active space (RAS), orbitals $3 b_{1}, 4 b_{1}, 2 a_{2}$ and $3 a_{2}$ in the complete active space (CAS) and orbitals $5 b_{1}$ and $4 a_{2}$ in auxiliary space (AUX). Therefore, in addition to all possible CSFs obtained by distributing four electrons among CAS orbitals, all CSFs obtained by single and double excitations from RAS to CAS, and from CAS to AUX space were included in the reference space. The final expansion space in the MR-AQCC calculations consisted of a total number of 67.5 million CSFs obtained with the 6-31G(d) basis set. This method will be henceforth denoted as MR-AQCC $(4 *, 4 *)$. An analogous procedure was used to construct the active and reference space for molecules $\mathbf{2} \mathbf{a}$ and $\mathbf{2} \mathbf{b}$ and transition structure 2TS.

Zero point vibrational energy (ZPVE) corrections to the total energies of all studied molecules was computed at the $\operatorname{CASSCF}(10,10) / 6-31 G(d)$ level of theory because MRAQCC method handles second derivatives calculations only numerically and harmonic force constants were computed by finite differences of the energy gradients. The harmonic vibrational frequencies were obtained by the SUSCAL program developed by Pulay et al. ${ }^{[54]}$ The minima on the potential energy surfaces were verified by frequency analysis. All of the CASSCF and MR-AQCC calculations have been performed employing Pople's 6-31G(d) basis set ${ }^{[55]}$ and using COLUMBUS suite of codes. ${ }^{[39,56,57]}$ The atomic orbital (AO) integrals and $A O$ gradient integrals have been computed with program module taken from DALTON. ${ }^{[58]}$ Geometry optimizations were performed in natural internal coordinates as defined by Fogarasi et al. ${ }^{[59]}$ by using the GDIIS method. ${ }^{60]}$

\section{RESULTS AND DISCUSSION}

Selected geometrical parameters for molecules $\mathbf{1 a}, \mathbf{1} \mathbf{b}$ and isomerization transition structure 1TS calculated by $\operatorname{CASSCF}(10,10) / 6-31 G(d)$ and MR-AQCC $\left(4^{*}, 4^{*}\right) / \operatorname{CASSCF}(10$, 10)/6-31G(d) computational methods are given in Table 2.

Detailed analysis of bond lengths in isomers $1 \mathbf{a}$ and 1b shows that they could be classified as distinct valence bond isomers as predicted in earlier computational studies. ${ }^{[25]}$ Focusing on the cyclobutadiene subunit, the bond length $d(C 2-C 7)$ obtained at the MR-AQCC level of theory in isomer 1a is $1.546 \AA$ whereas in isomer $\mathbf{1 b}$ it equals 1.362 $\AA$. Bond lengths $d(\mathrm{C} 7-\mathrm{C} 8)$ and $d(\mathrm{C} 2-\mathrm{C} 3)$ in isomer 1a are $1.356 \AA$ and $1.364 \AA$, respectively. The corresponding bond lengths in isomer $\mathbf{1 b}$ are $1.554 \AA$ and $1.538 \AA$, respectively. Moreover, analysis of the transition structure 1TS reveals that bond lengths $d(\mathrm{C} 2-\mathrm{C} 7), d(\mathrm{C} 7-\mathrm{C} 8)$ and $d(\mathrm{C} 2-\mathrm{C} 3)$ are $1.445 \AA, 1.442 \AA$, and $1.451 \AA$, respectively. This clearly indicates that cyclobutadiene subunit is localized in minimum structures and delocalized in transition structure (Figure 2), in analogy to trends observed in the previously studied parent cyclobutadiene and its derivatives. ${ }^{[13,23]}$ It is also evident that annelation results in some angular strain in the benzoquinone ring, as indicated by deviation of the $\mathrm{C} 2-\mathrm{C} 1-\mathrm{C} 6$ angle from $120^{\circ}$. Specifically, its value in isomer $1 \mathrm{a}$ is $112.7^{\circ}$, $111.1^{\circ}$ in isomer $\mathbf{1 b}$ and $111.8^{\circ}$ in transition structure $\mathbf{1 T S}$. This feature is not surprising due to a spillover of some angular strain caused by fusion of the strained four-membered ring and was also documented in previous calculations. ${ }^{[25]}$ We also notice that geometries obtained by

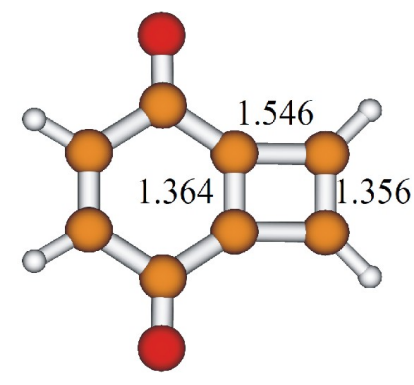

$1 \mathbf{a}$

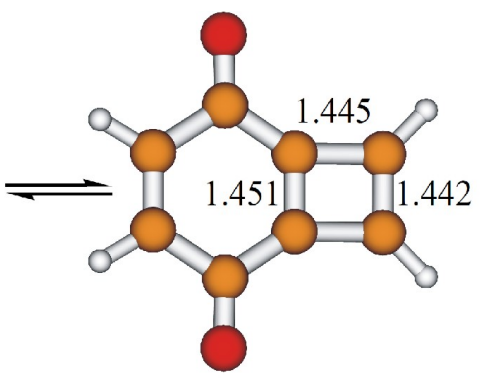

$1 T S$

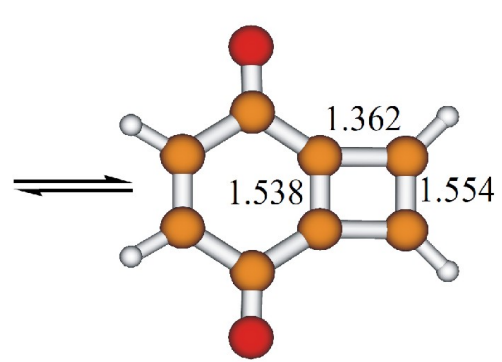

1b

Figure 2. Optimized geometries of molecules $1 \mathrm{a}, 1 \mathrm{~b}$ and corresponding transition structure 1TS with characteristic bond lengths (in $\AA$ ) obtained at the MR-AQCC $\left(4^{*}, 4^{*}\right) / \operatorname{CASSCF}(10,10) / 6-31 \mathrm{G}(\mathrm{d})$ level of theory. 
Table 2. Selected geometrical parameters(a) for molecules $1 \mathrm{a}, 1 \mathrm{~b}$ and their corresponding transition structure 1 TS obtained by using MR-AQCC $\left(4^{*}, 4^{*}\right) / \operatorname{CASSCF}(10,10) / 6-31 \mathrm{G}(\mathrm{d})$ and $\operatorname{CASSCF}(10,10) / 6-31 \mathrm{G}(\mathrm{d})$ and levels of theory, respectively. Distances are given in $\AA$, and angles are given in degrees

\begin{tabular}{|c|c|c|c|c|c|c|}
\hline \multirow[t]{2}{*}{ bond/angle } & \multicolumn{2}{|l|}{$1 a$} & \multicolumn{2}{|l|}{$1 b$} & \multicolumn{2}{|c|}{ 1TS } \\
\hline & $M R-A Q C C$ & CASSCF & $M R-A Q C C$ & CASSCF & $M R-A Q C C$ & CASSCF \\
\hline$d(\mathrm{C} 1-\mathrm{C} 2)$ & 1.464 & 1.458 & 1.457 & 1.459 & 1.452 & 1.452 \\
\hline$d(\mathrm{C} 2-\mathrm{C} 3)$ & 1.364 & 1.356 & 1.538 & 1.512 & 1.451 & 1.448 \\
\hline$d(\mathrm{C} 1-\mathrm{C} 6)$ & 1.502 & 1.494 & 1.499 & 1.495 & 1.501 & 1.495 \\
\hline$d(\mathrm{C5}-\mathrm{C} 6)$ & 1.354 & 1.352 & 1.360 & 1.356 & 1.356 & 1.354 \\
\hline$d(C 2-C 7)$ & 1.546 & 1.536 & 1.362 & 1.363 & 1.445 & 1.429 \\
\hline$d(\mathrm{C} 7-\mathrm{C} 8)$ & 1.356 & 1.358 & 1.554 & 1.546 & 1.442 & 1.460 \\
\hline$d(\mathrm{C} 1-\mathrm{O})$ & 1.233 & 1.214 & 1.236 & 1.213 & 1.239 & 1.216 \\
\hline $\mathrm{C} 1-\mathrm{C} 2-\mathrm{C} 3$ & 124.0 & 124.0 & 122.9 & 122.6 & 123.6 & 123.2 \\
\hline $\mathrm{C} 2-\mathrm{C} 1-\mathrm{C} 6$ & 112.7 & 112.9 & 111.1 & 112.1 & 111.9 & 112.5 \\
\hline $\mathrm{C} 1-\mathrm{C} 6-\mathrm{C} 5$ & 123.3 & 123.1 & 126.0 & 125.3 & 124.6 & 124.3 \\
\hline $\mathrm{C} 2-\mathrm{C} 3-\mathrm{C} 8$ & 89.9 & 90.0 & 90.3 & 90.7 & 89.8 & 90.2 \\
\hline $\mathrm{C} 7-\mathrm{C} 2-\mathrm{C} 1$ & 146.1 & 146.0 & 146.7 & 146.7 & 146.6 & 146.5 \\
\hline $\mathrm{C} 2-\mathrm{C} 1-\mathrm{O}$ & 125.2 & 125.1 & 126.7 & 126.1 & 126.0 & 125.6 \\
\hline \multirow[t]{2}{*}{ bond/angle } & \multicolumn{2}{|c|}{$2 a$} & \multicolumn{2}{|c|}{$2 b$} & \multicolumn{2}{|c|}{ 2TS } \\
\hline & $M R-A Q C C$ & CASSCF & $M R-A Q C C$ & CASSCF & $M R-A Q C C$ & CASSCF \\
\hline$d(\mathrm{C} 1-\mathrm{C} 2)$ & - & 1.443 & 1.416 & 1.417 & - & 1.435 \\
\hline$d(\mathrm{C} 2-\mathrm{C} 3)$ & - & 1.374 & 1.527 & 1.511 & - & 1.407 \\
\hline$d(\mathrm{C} 1-\mathrm{C} 6)$ & - & 1.482 & 1.442 & 1.461 & - & 1.480 \\
\hline$d(\mathrm{C} 5-\mathrm{C} 6)$ & - & 1.333 & 1.399 & 1.372 & - & 1.356 \\
\hline$d(\mathrm{C} 2-\mathrm{C} 7)$ & - & 1.374 & 1.391 & 1.372 & - & 1.491 \\
\hline$d(\mathrm{C} 7-\mathrm{C} 8)$ & - & 1.362 & 1.490 & 1.517 & - & 1.389 \\
\hline$d(\mathrm{C} 1-\mathrm{O})$ & - & 1.249 & 1.303 & 1.260 & - & 1.251 \\
\hline $\mathrm{C} 1-\mathrm{C} 2-\mathrm{C} 3$ & - & 121.6 & 122.1 & 121.8 & - & 121.6 \\
\hline $\mathrm{C} 2-\mathrm{C} 1-\mathrm{C} 6$ & - & 117.3 & 113.3 & 114.1 & - & 116.6 \\
\hline $\mathrm{C} 1-\mathrm{C} 6-\mathrm{C} 5$ & - & 121.1 & 124.5 & 124.0 & - & 121.7 \\
\hline $\mathrm{C} 2-\mathrm{C} 3-\mathrm{C} 8$ & - & 89.8 & 89.2 & 90.1 & - & 89.7 \\
\hline $\mathrm{C} 7-\mathrm{C} 2-\mathrm{C} 1$ & - & 148.6 & 148.6 & 148.0 & - & 148.7 \\
\hline $\mathrm{C} 2-\mathrm{C} 1-\mathrm{O}$ & - & 126.2 & 130.0 & 129.0 & - & 126.8 \\
\hline
\end{tabular}

(a) The numeration of atoms is shown in Figure 1.

the CASSCF and MR-AQCC methods are in qualitative agreement with the largest deviations in the transition structure where MR-AQCC method predicts larger delocalization in the cyclobutadiene subunit.

In contrast to the neutral molecule $\operatorname{CASSCF}(10,10) / 6$ $31 \mathrm{G}(\mathrm{d})$ and MR-AQCC $\left(4^{*}, 4^{*}\right) / \operatorname{CASSCF}(10,10) / 6-31 \mathrm{G}(\mathrm{d})$ calculations for the double protonated species yield contradictory results (Table 2). Namely, CASSCF calculations led to location of energy minima $\mathbf{2} \mathbf{a}$ and $\mathbf{2} \mathbf{b}$ and transition structure for their interconversion 2TS, while MR-AQCC method predicts that valence tautomerism is not operative here and that structure $\mathbf{2} \mathbf{b}$ best represents the molecule. Closer analysis of the calculated CASSCF geometries shows that only geometry of dication $\mathbf{2} \mathbf{b}$ resembles geometry of the related valence bond isomer (namely $\mathbf{1 b}$ ) encountered in the neutral molecule. In structure $\mathbf{2} \mathbf{a}$, the length of the bonds forming the cyclobutadiene ring are practically equal, while in the 2TS localization of the double bonds expected for isomer $\mathbf{2 a}$ are found. Both of these features strongly indicate that valence bond isomerism found in the parent molecule is not operative in the double protonated species (see also energetic properties reported below). It is of some interest to compare geometries of $\mathbf{1 b}$ and $\mathbf{2} \mathbf{b}$. In the latter the $\mathbf{C}=0$ bond is elongated due to the $\pi$-electron depopulation in this bonding region as result of formation of $\mathrm{O}-\mathrm{H}$ bond. Concomitantly, the presence of significant portion of the positive charge on the $\mathrm{C} 1$ atom results in the polarization of adjacent $\mathrm{CC}$ (C1-C2 and $\mathrm{C} 1-\mathrm{C} 6$, resp.) bonds, which as consequence become shortened, and to the opening of the $\mathrm{C} 6-\mathrm{C} 1-\mathrm{C} 2$ angle. As to the cyclobutadiene subunit, the annelated bond (C2-C3) undergoes only slight shortening, while the $\mathrm{C} 7-\mathrm{C} 8$ bond gets shorter by almost $0.06 \AA \AA$. On the 
Table 3. The weights of the leading configurations $\varphi_{1}$ and $\varphi_{2}$ in molecules $1 \mathrm{a}, 1 \mathrm{~b}$ and corresponding transition structure 1TS obtained by the MR-AQCC $\left(4^{*}, 4^{*}\right) / \operatorname{CASSCF}(10,10) / 6$ $31 \mathrm{G}(\mathrm{d})$ level of theory

\begin{tabular}{cccc}
\hline & $1 a$ & $1 b$ & $1 T S$ \\
\hline$\varphi_{1}$ & 0.592 & 0.027 & 0.302 \\
$\varphi_{2}$ & 0.019 & 0.585 & 0.311 \\
\hline
\end{tabular}

other hand, the double bonds ( $\mathrm{C} 2-\mathrm{C} 7$ and $\mathrm{C} 3-\mathrm{C} 8$ ), emanating from the sites of fusion become longer by ca $0.3 \AA$ indicating that the four-membered ring becomes less antiaromatic. This is corroborated by calculating Mulliken partial atomic charges for the two species, which predict a withdrawal of electronic densities upon protonation from all ring carbon atoms, with the largest ones from the $\mathrm{C} 1$ and C4 (from 0.39 to 0.29 , in $\mathbf{1} \mathbf{b}$ and $\mathbf{2} \mathbf{b}$, respectively).

Table 3 summarizes the weights of the leading electronic configurations $\varphi_{1}$ and $\varphi_{2}$ in isomers $1 \mathrm{a}, \mathbf{1} \mathbf{b}$ and corresponding transition structure 1TS. It appears that the electronic configuration in $\mathbf{1 a}$ and $\mathbf{1} \mathbf{b}$ is $\left(3 b_{1}\right)_{2}\left(4 b_{1}\right)_{2}\left(2 a_{2}\right)_{0}$ and $\left(3 b_{1}\right)_{2}\left(2 a_{2}\right)_{2}\left(4 b_{1}\right)_{0}$, respectively, whereas in the transition state 1TS these two electronic configurations are mixed with a similar weight. Figure 3 schematically shows related orbitals of isomers $\mathbf{1 a}$ and $\mathbf{1} \mathbf{b}$.

Finally, we shall focus on the energetic properties of the studied species. In Table 4, energy barriers for isomerization reactions for neutral and double protonated isomers with and without ZPVE energy correction as calculated by $\operatorname{CASSCF}(10,10) / 6-31 G(d)$ and MR-AQCC $\left(4^{*}, 4^{*}\right) / \operatorname{CASSCF}(10$, 10)/6-31G(d) methods are listed.

Analysis of the data in Table 4 shows that isomer 1a is by $4.1 \mathrm{kcal} \mathrm{mol}^{-1}$ more stable than isomer $\mathbf{1 b}$ at the $\operatorname{CASSCF}(10,10) / 6-31 G(d)$ level of theory, whereas at the MR-AQCC $\left(4^{*}, 4^{*}\right) / \operatorname{CASSCF}(10,10) / 6-31 \mathrm{G}$ (d) level of theory this difference is merely $0.3 \mathrm{kcal} \mathrm{mol}^{-1}$, respectively. Zeropoint vibrational energies, calculated at the $\operatorname{CASSCF}(10,10)$ $/ 6-31 \mathrm{G}(\mathrm{d})$ level of theory, differ only by $0.2 \mathrm{kcal} \mathrm{mol}^{-1}$, thus affecting the relative stabilities of the isomers only slightly (Table 4). As expected, ZPVE for the transition structures are lower by ca. $2 \mathrm{kcal} \mathrm{mol}^{-1}$ which is a consequence of one inactive vibration in total zero-point vibrational energy. In

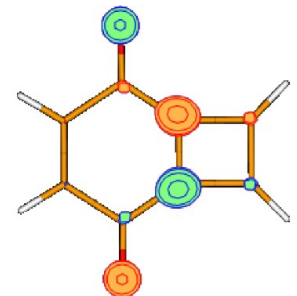

$2 \mathrm{a}_{2}$

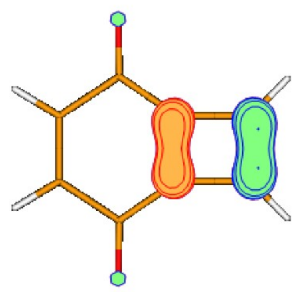

$4 b_{1}$

1a<smiles>[134IH]</smiles>

$4 b_{1}$

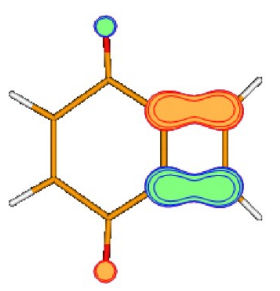

$2 \mathrm{a}_{2}$

$1 \mathbf{b}$
Figure 3. Schematic representation of $2 a_{2}$ and $4 b_{1}$ orbitals in isomers $1 \mathrm{a}$ and $1 \mathrm{~b}$.

the case of diprotonated isomers, total energies of minima and transition structure could be calculated only at the $\operatorname{CASSCF}(10,10) / 6-31 G(d)$ level of theory. At this level of theory structures $2 \mathrm{a}$ and $\mathbf{2 T S}$ were found to be by $11.8 \mathrm{kcal}$ $\mathrm{mol}^{-1}$ less stable than $\mathbf{2} \mathbf{b}$, whereas the barrier for isomerization from isomer $\mathbf{2 a}$ and transition structure $\mathbf{2 T S}$ drops to only $0.4 \mathrm{kcal} \mathrm{mol}^{-1}$. Inclusion of ZPVEs leads to disappearance of the energy barrier and isomerization becomes spontaneous. This conclusion is further corroborated by calculations at the MR-AQCC $\left(4^{*}, 4^{*}\right) / \operatorname{CASSCF}(10$, 10)/6-31G(d) level of theory which predict that only one minimum (i.e. structure $\mathbf{2 b}$ ) exists at the potential energy surface. Thus, we can safely conclude that CASSCF method fails to give reliable answer to the question whether

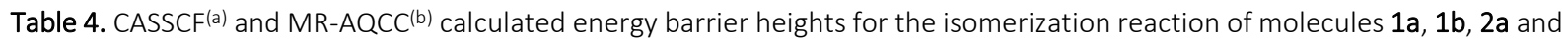
$2 \mathrm{~b}$ with and without ZPVE correction(c), respectively. All values are given in $\mathrm{kcal}^{\mathrm{mol}}{ }^{-1}$

\begin{tabular}{|c|c|c|c|c|}
\hline molecule & CASSCF & CASSCF+ZPVE & MR-AQCC & MR-AQCC+ZPVE \\
\hline $1 a$ & 6.7 & 4.6 & 6.7 & 4.6 \\
\hline $1 b$ & 2.6 & 0.7 & 6.4 & 4.5 \\
\hline $2 a$ & 0.4 & -0.8 & - & - \\
\hline $2 b$ & 12.2 & 10.9 & - & - \\
\hline
\end{tabular}

\footnotetext{
(a) $\operatorname{CASSCF}(10,10) / 6-31 \mathrm{G}(\mathrm{d})$.

(b) MR-AQCC $\left(4^{*}, 4^{*}\right) / 6-31 G(d) / \operatorname{CASSCF}(10,10) / 6-31 G(d)$.

(c) ZPVE was calculated at the $\operatorname{CASSCF}(10,10) / 6-31 \mathrm{G}(\mathrm{d})$ level of theory.
} 
valence bond isomerism operates in protonated cyclobutadieno- $p$-benzoquinone.

Inspection of Table 4 shows that the energy barrier for interconversion of isomer $\mathbf{1 a}$ to isomer $\mathbf{1 b}$ calculated at the $\operatorname{CASSCF}(10,10) / 6-31 \mathrm{G}(\mathrm{d})$ level of theory is $6.7 \mathrm{kcal}$ $\mathrm{mol}^{-1}$, and $2.6 \mathrm{kcal} \mathrm{mol}^{-1}$ for interconversion of isomer $\mathbf{1 b}$ into isomer 1a, respectively. Inclusion of ZPVE correction diminishes energy barrier to $4.6 \mathrm{kcal} \mathrm{mol}^{-1}$ for the former, and only to $0.7 \mathrm{kcal} \mathrm{mol}^{-1}$ for the latter process. These results are close to previously reported $\operatorname{CASSCF}(10,10) / / G V B 2$ calculated energy barrier values of 5.9 of $\mathrm{kcal} \mathrm{mol}^{-1}$ for the interconversion of isomer $\mathbf{1 a}$ to isomer $\mathbf{1 b}$ and $0.8 \mathrm{kcal} \mathrm{mol}^{-1}$ for the interconversion of isomer $\mathbf{1 b}$ to isomer $\mathbf{1 a} .^{[25]}$ The situation is quite different at the MR-AQCC $\left(4^{*}, 4^{*}\right) / C A S S C F$ $(10,10) / 6-31 G(d)$ level of theory which gives an almost symmetric barrier with heights of $6.4 \mathrm{kcal} \mathrm{mol}^{-1},(4.5 \mathrm{kcal}$ $\mathrm{mol}^{-1}$ with ZPVE correction) and $6.7 \mathrm{kcal} \mathrm{mol}^{-1}(4.6 \mathrm{kcal}$ $\mathrm{mol}^{-1}$ with ZPVE correction) relative to isomers $\mathbf{1 b}$ and $\mathbf{1 a}$, respectively. It is noteworthy that these results are significantly different than those obtained employing CASPT2(10, 10)//GVB2 level of theory, ${ }^{[25]}$ where the ZPVE corrected energy barrier of $5.3 \mathrm{kcal} \mathrm{mol}^{-1}$ for the interconversion of isomer $\mathbf{1 a}$ to $\mathbf{1 b}$, and only $0.3 \mathrm{kcal} \mathrm{mol}^{-1}$ for the interconversion of isomer $\mathbf{1} \mathbf{b}$ to $\mathbf{1 a}$ were found. The main reason for this discrepancy is due to the fact that PT2 procedure describes dynamical correlation only to the second order and that results in Ref. [25] were obtained by single point calculations since geometry optimization procedures were not available for this computational level. Hence, the transition structure in the previous study ${ }^{[25]}$ could not be precisely described. Thus the present results obtained by more advanced MR-AQCC $\left(4^{*}, 4^{*}\right) / \operatorname{CASSCF}(10$, 10)/6-31G(d) method provide more realistic description of the studied system strongly indicating that isomers $\mathbf{1 a}$ and $\mathbf{1 b}$ are practically isoenergetic and that they can exist as distinct molecules under appropriate conditions.

Comparison of the calculated interconversion energy barriers to the MR-AQCC benchmark value for cyclobutadiene automerization which is $6.3 \mathrm{kcal} \mathrm{mol}^{-1},{ }^{[13]}$ reveals that annelation of cyclobutadiene to $p$-quinone ring lowers energy barriers for the interconversion of isomers $\mathbf{1 a}$ and $\mathbf{1} \mathbf{b}$ by ca. $2 \mathrm{kcal} \mathrm{mol}^{-1}$ ( 4.6 and $4.5 \mathrm{kcal} \mathrm{mol}^{-1}$, respectively). This implies that isomers $\mathbf{1 a}$ and $\mathbf{1} \mathbf{b}$ are not kinetically stable at room temperature where they freely interconvert between two forms. However, their existence could be possible at very low temperatures as experimentally suggested for 1,3dimethylcyclobutadiene. ${ }^{[11]}$ On the other hand, CASSCF and MR-AQCC calculations give contradictory results for diprotonated species. The CASSCF calculations erroneously predict existence of two valence isomers, $\mathbf{2} \mathbf{a}$ and $\mathbf{2} \mathbf{b}$, whereas the MR-AQCC calculations predict that geometry of double protonated species could be best described by structure $\mathbf{2 b}$. This nicely illustrates the crucial role of dynamic correlation and the need for using a highly-correlated theoretical method including geometry optimization in studied molecules.

\section{CONCLUSIONS}

Complete active space (CASSCF) and multireference average coupled cluster (MR-AQCC) calculations were performed in order to study valence bond isomerism in neutral and diprotonated cyclobutadieno- $p$-benzoquinones. Energy barriers with included zero-point energy correction obtained by MR-AQCC $\left(4^{*}, 4^{*}\right) / \operatorname{CASSCF}(10,10) / 6-31 G(d)$ level of theory for valence bond isomerization of neutral molecules $\mathbf{1 a}$ to $\mathbf{1 b}$ and from $\mathbf{1 b}$ to $\mathbf{1 a}$ via transition state $\mathbf{1 T S}$ are 4.6 and $4.5 \mathrm{kcal} \mathrm{mol}^{-1}$, respectively. Notably, energy barriers are lower by ca. $2 \mathrm{kcal} \mathrm{mol}^{-1}$ as compared to the MRAQCC benchmark cyclobutadiene automerization energy barrier of $6.3 \mathrm{kcal} \mathrm{mol}^{-1} .{ }^{[13]}$ This finding is at variance with previously reported results of CASPT2 $(10,10) / / G V B 2$ calculations by Maksic and coworkers ${ }^{[25]}$ who found that isomer $\mathbf{1 b}$ is not kinetically stable at the potential energy surface due to the small interconversion barrier of only $0.3 \mathrm{kcal}$ $\mathrm{mol}^{-1}$. It is strongly pointed out that theoretical treatment of the studied systems requires multireference methods capable of accurate reproduction of the Born-Oppenheimer potential energy surface (PES) along the isomerization pathways.

For double protonated cyclobutadieno- $p$-benzoquinones, $\operatorname{CASSCF}(10,10) / 6-31 G(d)$ method erroneously predicts existence of two energy minima, $\mathbf{2} \mathbf{a}, \mathbf{2} \mathbf{b}$, and transition structure 2TS for their interconversion. However, if more advanced MR-AQCC $\left(4^{*}, 4^{*}\right) / \operatorname{CASSCF}(10,10) / 6-31 \mathrm{G}(\mathrm{d})$ method (which includes dynamic electronic correlation as well) is used, only structure $\mathbf{2} \mathbf{b}$ was located at the potential energy surface.

Acknowledgment. Financial support of this work by the Ministry of Science, Education and Sport of Croatia through the project no. 098-0982933-2920 is acknowledged. Our thanks go also to the Computing Centre of the University of Zagreb (SRCE) for granting computation time on the ISABELLA cluster.

\section{REFERENCES}

[1] M. Sebastian, M. Nieger, D. Szieberth, L. Nyulaszi, E. Niecke, Angew. Chem. Int. Edit. 2004, 43, 637.

[2] W. W. Schoeller, C. Begemann, E. Niecke, D. Gudat, J. Phys. Chem. A 2001, 105, 10731.

[3] E. Niecke, A. Fuchs, M. Nieger, Angew. Chem. Int. Edit. 1999, 38, 3028.

[4] A. Rodriguez, R. A. Olsen, N. Ghaderi, D. Scheschkewitz, F. S. Tham, L. J. Mueller, G. Bertrand, Angew. Chem. Int. Edit. 2004, 43, 4880. 
[5] T. Bally, S. Masamune, Tetrahedron 1980, 36, 343.

[6] G. Maier, Angew. Chem. Int. Edit. 1974, 13, 425.

[7] G. F. Emerson, L. Watts, and R. Pettit, J. Am. Chem. Soc. 1965, 87, 131.

[8] P. Reeves, J. Henery, and R. Pettit, J. Am. Chem. Soc. 1969, 91, 5888.

[9] O. L. Chapman, C. L. McIntosh, J. Pacansky, J. Am. Chem. Soc. 1973, 95, 244.

[10] D. J. Cram, M. E. Tanner, R. Thomas, Angew. Chem. Int. Edit. 1991, 30, 1024.

[11] Y. M. Legrand, A. D. Van Lee, M. Barboiu, Science 2010, 329, 299.

[12] A. Balkova, R. J. Bartlett, J. Chem. Phys. 1994, 101, 8972.

[13] M. Eckert-Maksić, M. Vazdar, M. Barbatti, H. Lischka, Z. B. Maksić, J. Chem. Phys. 2006, 125, 064310.

[14] D. Scheschkewitz, Science 2010, 330, 1047.

[15] Y. M. Legrand, A. Van Der Lee, M. Barboiu, Science 2010, 330, 1047.

[16] I. V. Alabugin, B. Gold, M. Shatruk, K. Kovnir, Science 2010, 330, 1047.

[17] H. S. Rzepa, Chem. Commun. 2011, 47, 1851.

[18] J. C. Sancho-García, J. Pittner, P. Čársky, I. Hubač, J. Chem. Phys. 2000, 112, 8785.

[19] J. Shen, T. Fang, S. Li, Y. Jiang, J. Phys. Chem. A 2008, $112,12518$.

[20] D. Lefrancois, M. Wormit, A. Dreuw, J. Chem. Phys. 2015, 143, 124107.

[21] I. Antol, M. Eckert-Maksić, H. Lischka, Z. B. Maksić, ChemPhysChem 2004, 5, 975.

[22] I. Despotovic, M. Eckert-Maksic, Z. B. Maksic, D. M. Smith, J. Phys. Chem. A 2003, 107, 10396.

[23] M. Eckert-Maksić, H. Lischka, Z. B. Maksić, M. Vazdar, J. Phys. Chem. A, 2009, 113, 8351.

[24] M. L. McKee, M. Balci, H. Kilic, E. Yurtsever, J. Phys. Chem. A 1998, 102, 2351.

[25] Z. B. Maksic, I. Petanjek, M. Eckert-Maksic, I. Novak, J. Phys. Chem. A 1998, 102, 10710.

[26] T. K. Ha, Mol. Phys. 1983, 49, 1471.

[27] S. E. McKay, P. Kiprof, A. B. Brown, J. Mol. Struc.THEOCHEM 1996, 368, 197.

[28] Y. Yamamoto, T. Arakawa, K. Itoh, Organometallics 2004, 23, 3610.

[29] C.-C. Zeng, J. Y. Becker, J. Org. Chem. 2004, 69, 1053.

[30] E. Golas, E. Lewars, J. F. Liebman, J. Phys. Chem. A 2009, 113, 9485.

[31] P. G. Szalay, R. J. Bartlett, Chem. Phys. Lett. 1993, $214,481$.

[32] P. G. Szalay, R. J. Bartlett, J. Chem. Phys. 1995, 103, 3600.

[33] P. G. Szalay, in: Modern Ideas in Coupled-Cluster Methods, R. J. Bartlett (Ed.), World Scientific, Singapore, 1997, p. 81.

[34] P. G. Szalay, T. Mueller, G. Gidofalvi, H. Lischka, R.
Shepard, Chem. Rev. 2012, 112, 108.

[35] M. W. Schmidt, M. S. Gordon, Annu. Rev. Phys. Chem. 1998, 49, 233.

[36] G. Das, J. Chem. Phys. 1973, 5104.

[37] K. A. Nguyen, M. S. Gordon, J. Am. Chem. Soc. 1995, 117, 3835.

[38] G. Das, A. C. Wahl, J. Chem. Phys. 1972, 56, 1769.

[39] H. Lischka, R. Shepard, R. M. Pitzer, I. Shavitt, M. Dallos, T. Müller, P. G. Szalay, M. Seth, G. S. Kedziora, S. Yabushita, Z. Zhang, Phys. Chem. Chem. Phys. 2001, 3, 664 .

[40] B. O. Roos, Adv. Chem. Phys. 1987, 69, 399.

[41] H. Lischka, M. Dallos, R. Shepard, Mol. Phys. 2002, 100, 1647.

[42] P. G. Szalay, A. Karpfen, H. Lischka, Chem. Phys. 1989, 130, 219.

[43] I. Antol, M. Eckert-Maksic, H. Lischka, J. Phys. Chem. A 2004, 108, 10317.

[44] I. Antol, M. Eckert-Maksic, T. Mueller, M. Dallos, H. Lischka, Chem. Phys. Lett. 2003, 374, 587.

[45] M. Barbatti, G. Granucci, M. Persico, M. Ruckenbauer, M. Vazdar, M. Eckert-Maksic, H. Lischka, J. Photochem. Photobiol. A Chem. 2007, 190, 228.

[46] I. Antol, M. Eckert-Maksic, M. Barbatti, H. Lischka, J. Chem. Phys. 2007, 127, 3173.

[47] I. Antol, M. Vazdar, M. Barbatti, M. Eckert-Maksic, Chem. Phys. 2008, 349, 308.

[48] I. Antol, M. Barbatti, M. Eckert-Maksic, H. Lischka, Monatsh. Chem. 2008, 139, 319.

[49] M. Vazdar, M. Eckert-Maksic, M. Barbatti, H. Lischka, Mol. Phys. 2009, 107, 845.

[50] M. Eckert-Maksic, M. Vazdar, M. Ruckenbauer, M. Barbatti, T. Mueller, H. Lischka, Phys. Chem. Chem. Phys. 2010, 12, 12719.

[51] S. Faraji, M. Vazdar, V. S. Reddy, M. Eckert-Maksic, H. Lischka, H. Koeppel, J. Chem. Phys. 2011, 135, 154310.

[52] R. Shepard, H. Lischka, P. G. Szalay, T. Kovar, M. Ernzerhof, J. Chem. Phys. 1992, 96, 2085.

[53] A. Bunge, J. Chem. Phys. 1970, 53, 20.

[54] P. Pulay, G. Fogarasi, G. Pongor, J. E. Boggs, A. Vargha, J. Am. Chem. Soc. 1983, 105, 7037.

[55] W. J. Hehre, K. Ditchfield, J. A. Pople, J. Chem. Phys. 1972, 56, 2257.

[56] H. Lischka, R. Shepard, F. B. Brown, I. Shavitt, Int. J. Quantum Chem. Symp. 1981, 15, 91.

[57] H. Lischka, R. Shepard, I. Shavitt, R. M. Pitzer, M. Dallos, T. Müller, P. G. Szalay, F. B. Brown, R. Ahlrichs, H. J. Boehm, A. Chang, D. C. Comeau, R. Gdanitz, H. Dachsel, C. Ehrhardt, M. Ernzerhof, P. Höchtl, S. Irle, G. Kedziora, T. Kovar, V. Parasuk, M. J. M. Pepper, P. Scharf, H. Schiffer, M. Schindler, M. Schüler, M. Seth, E. A. Stahlberg, J.-G. Zhao, S. 
Yabushita, Z. Zhang, M. Barbatti, S. Matsika, M. Schuurmann, D. R. Yarkony, S. R. Brozell, E. V. Beck, J.-P. Blaudeau, COLUMBUS, an ab initio electronic structure program, Release 5.9.1, 2006, www.univie.ac.at/columbus.

[58] T. Helgaker, H. J. A. Jensen, P. Jørgensen, J. Olsen, K. Ruud, H. Ågren, T. Andersen, K. L. Bak, V. Bakken, O. Christiansen, P. Dahle, E. K. Dalskov, T. Enevoldsen,
H. Heiberg, H. Hettema, D. Jonsson, S. Kirpekar, R. Kobayashi, H. Koch, K. V. Mikkelsen, P. Norman, M. J. Packer, T. Saue, P. R. Taylor, O. Vahtras, DALTON, an $a b$ initio electronic structure program, Release 1.0, 1997.

[59] G. Fogarasi, X. Zhou, P. W. Taylor, and P. Pulay, J. Am. Chem. Soc. 1992, 114, 8191.

[60] P. Csaszar, and P. Pulay, J. Mol. Struct. 1984, 114, 31. 